\title{
UNMANNED AERIAL VEHICLE USE FOR WOOD CHIPS PILE VOLUME ESTIMATION
}

\author{
M. Mokroša, M. Tabačák ${ }^{a}$, M. Lieskovský ${ }^{b}$, M. Fabrika ${ }^{a}$ \\ ${ }^{a}$ Dept. of Forest Management and Geodesy, Technical University in Zvolen, Slovak Republic, (martin.mokros, xtabacak, \\ fabrika)@tuzvo.sk \\ ${ }^{\mathrm{b}}$ Dept. of Forest Harvesting, Logistics and Meliorations, Technical University in Zvolen, Slovak Republic, lieskovsky@ tuzvo.sk
}

Commission ICWG I/Vb

KEY WORDS: Unmanned aerial vehicle, wood chips pile, DJI Phantom, photogrammetry

\begin{abstract}
:
The rapid development of unmanned aerial vehicles is a challenge for applied research. Many technologies are developed and then researcher are looking up for their application in different sectors. Therefore, we decided to verify the use of the unmanned aerial vehicle for wood chips pile monitoring.

We compared the use of GNSS device and unmanned aerial vehicle for volume estimation of four wood chips piles. We used DJI Phantom 3 Professional with the built-in camera and GNSS device (geoexplorer 6000). We used Agisoft photoscan for processing photos and ArcGIS for processing points.

Volumes calculated from pictures were not statistically significantly different from amounts calculated from GNSS data and high correlation between them was found $(\mathrm{p}=0.9993)$. We conclude that the use of unmanned aerial vehicle instead of the GNSS device does not lead to significantly different results. Tthe data collection consumed from almost 12 to 20 times less time with the use of UAV. Additionally, UAV provides documentation trough orthomosaic.
\end{abstract}

\section{INTRODUCTION}

Nowadays is no longer need to emphasize huge development in the unmanned aerial vehicle (drone) sector. There is a plenty type of drones from nano $(<5 \mathrm{~kg})$ to large $(>200 \mathrm{~kg}$ ) if we are comparing it based on the weight (Anderson and Gaston 2013). Crucial is also the way how drones take-off and land. We can distinguish them to two key categories: horizontal take-off (fixed wing) and vertical take-off (rotary-wing) drones (Tang and Shao, 2015). There are many possible ways how to divide drones to categories (Blyenburgh, 2014). It is very helpful for decision making when we considering drone usage for a project.

Researchers created several studies about drone usage for forestry practice in recent years. Mostly because of their benefits. The most significant advantage is the much lower price than manned aircraft (device cost and also operation cost). Furthermore, possibility to achieve better resolution and also the flexibility of use.

The studies are focusing on determining forest health (Dunford et al., 2009; Michez, et al., 2016), forest condition monitoring (Koh and Wich, 2012; Paneque-Galvez et al., 2014).Moreover they are focusing on crown analysis (Lisein et al., 2013; Wallace et al., 2013; Chianucci et al., 2015), tree species identification, tree height derivation (Wallace et al., 2012; Zarco-Tejada et al., 2014) and also on diameter at breast height derivation (Chischolm et al., 2013).

However, it should be mentioned that one of the first goals of research focusing on the use of drones for forestry were forest fires monitoring and management (Ambrosia et al., 2003; Ollero, 2006). From 2006 to 2010, NASA and the US Forest Service presented a drone that was able to fly 24 hours for the forest fires management purpose (Tang and Shao, 2015).
In this work we are focusing on drone use in forestry but for one of the last stages of processing wood. Which is wood chips storing. Wood chips piles stored at the warehouse are constantly changing their volume and also the placement in the storage area. It is crucial to have information about the current volume and placement of the wood chips piles. We decided to verify the drone use to monitor the real state of the wood chips pile as an alternative to the currently used GNSS.

\section{STUDY SITES}

For purposes of the study, four wood chips piles were selected. Each wood chip pile was stored on different storage without any shelter (Figure 1). They differed with total volume, area and by the layout on the storage. Mostly it was energetic woodchips stored within heating plant complex.

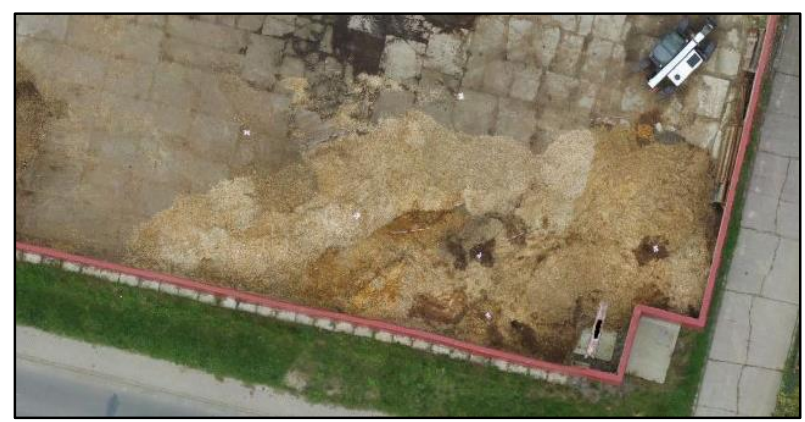

Figure 1. The wood chips pile orthomosaic example (Poltár)

\section{DATA COLLECTION}

\subsection{Unmanned aerial vehicle}

We used DJI Phantom 3 Professional for imagery. It is quadcopter with built-in camera Sony Exmor 1 / 2.3 "with Effective pixels: 12.4 megapixels. We choose this device because 
of its relatively low cost and all-in-one solution (Built-in camera, gimbal, software, remote control). Before the flight, we laid out reference targets and also reference sticks on the pile and close to the pile, for scaling purposes. The flight was carried out at a $20 \mathrm{~m}$ height above the ground with parallel strips to achieve at least $80 \%$ forward overlap and at least $60 \%$ lateral overlap (Figure 2). We used the waypoints mode for autonomous flight within the DJI GO application. First, we collected waypoints position by UAV to plan the strips. Then UAV follows these waypoints in set speed and automatically took pictures. When the plan finished landing was carried out manually.

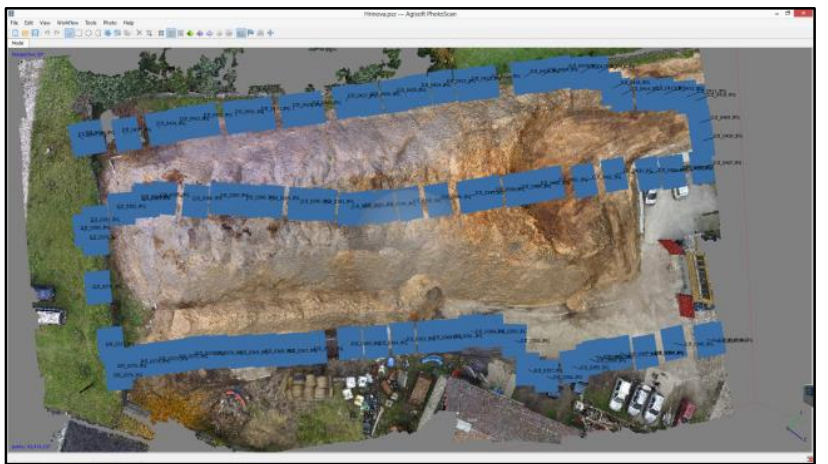

Figure 2. Example of flight path shown by blue rectangles that represent the photo positions (Hriňová)

\subsection{GNSS device}

Trimble GeoExplorer 6000 with real-time correction was used to collect points on piles and also around the piles with error under $2 \mathrm{~cm}$. We distributed the points within the plot with regard to capturing the surface of the pile as detailed as possible. The observation time on every point was 2 minutes. In several cases, the error under $2 \mathrm{~cm}$ was not possible to achieve because near high walls were very near to pile.

\section{DATA PROCESSING}

\subsection{Volume from GNSS}

To calculate the wood chips pile volume ArcGIS software was used. We used two point clouds as input data. In the first layer, we located points that were around the pile (on the panel floor) and saved them separately. This point cloud was used to calculate the digital terrain model. The second point cloud combined first point cloud with points collected on woodchips pile. The second point cloud was used to derive the digital surface model (Figure $3)$.

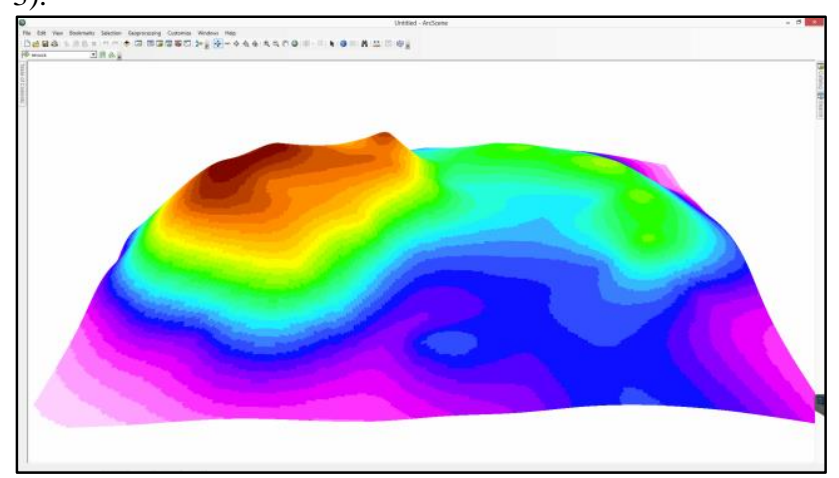

Figure 3. Digital surface model from GNSS points (Revúca)

The first step of the workflow (after importing the data) was TIN creation by Create TIN module. This method has proven to be the most appropriate compared with IDW, Kriging or spline interpolation. The second step was the conversion of a TIN to raster layers using the module TIN to Raster. In this module, we cannot determine the size of the cells. Therefore, we changed the grid size by module Resample to $0.1 \mathrm{~m}$ for DSM and also DTM layer. The next step was to subtract DSM from DTM by Minus module. Then minus layer was multiplied by cell resolution within Raster Calculator module. The resulting raster layer had information about the volume. To calculate the total volume of the pile we used Zonal Statistics module. Input was a layer from Raster Calculator module and polygon feature layer of the pile. The whole workflow was programmed within model builder, and it is graphically displayed in Figure 4.

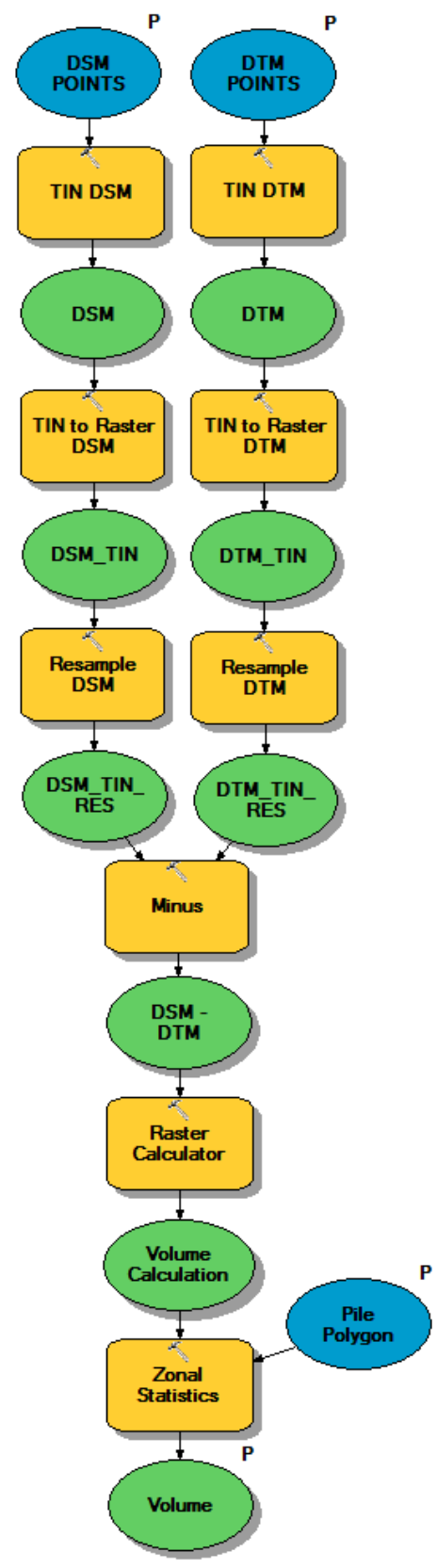

Figure 4. ArcGIS workflow for volume calculation

\subsection{Volume from UAV}

Agisoft Photoscan was used to align pictures, build dense point cloud and calculating volume. The first step before processing 
picture we calibrated camera within Agisoft Lens software. We displayed chessboard on a monitor, and we took pictures from multiple sides and angles. To align pictures we used High accuracy and Generic pair preselection. Firstly photos are aligned to groups of photos with reduced resolution and then groups are aligned in set resolution. After successful aligning we created dense point cloud with high quality and with Aggressive depth filtering (Figure 5). When the dense point cloud was generated, we scaled point cloud using reference sticks. Red and white parts divided reference sticks with a $20 \mathrm{~cm}$ length. We placed two markers on reference stick. Depends on how many parts were between those markers the distance was calculated and we wrote scale bar distance. We placed four sticks on every pile to be sure that at least one of them will be clear on pictures. After scaling mesh was built with high quality.

Before volume calculation, everything that is not the pile must be deleted from the model. Then all holes were closed, and volume was calculated.

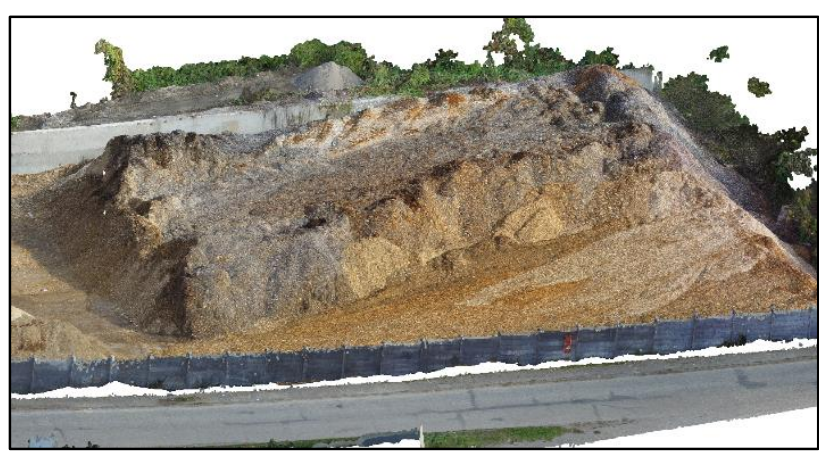

Figure 5. Dense point cloud of wood chips pile (Hnúšt’a)

\section{RESULTS}

A number of strips depended on pile width and varied from 3 to 6 strips. A number of pictures ranged from 52 to 138 (Table 1).

\begin{tabular}{|l|c|c|c|c|}
\hline & Poltár & Hnúšt’a & Revúca & Hriňová \\
\hline Strips & 4 & 6 & 6 & 3 \\
\hline Pictures & 52 & 114 & 138 & 92 \\
\hline
\end{tabular}

Table 1. Number of strips and pictures for each pile

When we compare a number of points used to derive volume we can see the first significant difference between GNSS and UAV approaches (Table 2). A number of points measured by GNSS varied from 24 to 60 and number of points derived from photos ranged from 2.2 million to 43.4 million.

\begin{tabular}{|l|c|c|c|c|}
\hline & Poltár & Hnúšt’a & Revúca & Hriňová \\
\hline GNSS & 24 & 48 & 50 & 60 \\
\hline UAV & 2.2 mil. & 41.2 mil. & 20.5 mil. & 43.4 mil. \\
\hline
\end{tabular}

Table 2. Number of used points for volume calculation

The main result of the study was volumes of wood chips piles. Volumes calculated from GNSS points varied from $376 \mathrm{~m}^{3}$ to $4430 \mathrm{~m}^{3}$. Volumes calculated from pictures ranged from $426 \mathrm{~m}^{3}$ to $4930 \mathrm{~m}^{3}$. Differences between methods ranged from $50 \mathrm{~m}^{3}$ to $583 \mathrm{~m}^{3}$. In relative values, differences ranged from $7.9 \%$ to $11.7 \%$ (Table 3)

We compared derived volumes with paired t-test in Rstudio. There is a strong correlation between GNSS and UAV results (0.9993 and Sig. 0.001). Confidence interval (0.05) of the difference is from -735 to 22 . Methods are not statistically significantly different from each other ( $\mathrm{p}$. value $=0.058$ ). However, the p.value is not a strong.

\begin{tabular}{|c|c|c|c|c|}
\hline & Poltár & Hnúšt’a & Revúca & Hriňová \\
\hline $\begin{array}{c}\text { GNSS Vol. } \\
(\mathrm{m} 3)\end{array}$ & 376 & 4430 & 3417 & 4277 \\
\hline $\begin{array}{c}\text { UAV Vol. } \\
(\mathrm{m} 3)\end{array}$ & 426 & 4930 & 3710 & 4860 \\
\hline $\begin{array}{c}\text { Diference } \\
(\mathrm{m} 3)\end{array}$ & 50 & 500 & 293 & 583 \\
\hline Diference (\%) & 11.7 & 10.1 & 7.9 & 12.0 \\
\hline
\end{tabular}

Table 3. Derived volumes from GNSS and UAV

Net time for data collection for GNSS and UAV is in Table 4. For both approaches time to prepare the device and pack the devices should be added. For UAV time to place the scaling objects should also be add.

\begin{tabular}{|l|c|c|c|c|}
\hline & Poltár & Hnúšt’a & Revúca & Hriňová \\
\hline GNSS & 72 & 192 & 150 & 180 \\
\hline UAV & 6 & 11 & 13 & 9 \\
\hline
\end{tabular}

Table 4. Data collection time for GNSS and UAV

Postprocessing of both approaches is comparable by time and user difficulty means. We have made the workflow for processing data from GNSS within ArcGIS what leads to simplifying the whole process. Agisoft has also option to automatize processes within Python language.

However, for both processes user interaction is needed in some stage of the processing.

\section{CONCLUSION}

In all four cases, wood chips piles proved one-sided difference calculation of the volume. Specifically, the volume calculated from the points of GNSS device was lower on average $10.4 \%$ $(356.5 \mathrm{~m} 3)$ than the volume calculated from the UAV photos. This fact is mainly attributable to the significantly higher generalization of piles surface using points from GNSS device. An average number of points from GNSS was 46 points and from UAV 26,836,968 points.

Piles stored near to high walls also led to worse GNSS accuracy. This situation was in two piles (Poltár, Hriňová). The relative difference of those two piles was $11.7 \%$ and $12 \%$. The other two piles without high walls near to pile showed relative difference $10.1 \%$ and $7.9 \%$. Lowest relative difference was on a pile on open storage without any walls.

We believe that the use of UAV leads to more detailed results. The time to collect data is significantly lower. Also from UAV photos orthomosaic can be made for documentation.

\section{DISCUSSION}

Reference stick was used as an object for point cloud scaling. Some more accurate object should be considered. In some cases, it was difficult to identify the transition between colors.

In cases where the pile is not too large, just camera on the telescopic pole should be considered. The camera can capture photos simultaneously during the walk around a pile. Moreover, same post processing workflow as we used for photos from UAV can be employed. Alternatively, the use of stereo camera pointing 
on the pile from some height can be used continuously and give the volume of the pile on a daily basis.

\section{ACKNOWLEDGEMENTS}

The research was carried out within the framework of the project APVV-0069-12, entitled "New technology of managing the nature (NEWTON)".

\section{REFERENCES}

Ambrosia, VG., Wegener, SS., Sullivan, DV., Buechel, SW., Brass, JA., Dunagan, SE., Higgins, RG., Hildum, EA., Schoenung, SM., 2002. Demonstrating UAV-Acquired RealTime Thermal Data Over Fires. Photogrammetric Engineering and Remote Sensing, 69(4), pp. 391-402.

Anderson, K., Gaston, KJ., 2013. Lightweight unmanned aerial vehicles will revolutionize spatial ecology. Front Ecol Environ, 11(3), pp. 138-146.

van Blyenburgh, P., 2014. RPAS: The Global Perspective $-12^{\text {th }}$ Edition. Blyenburgh \& CO. ISSN: 2270-6061.

Dunford, R., Michel, K., Gagnage, M., Piégay, H., Trémelo, ML., 2009. Potential and constraintsof Unmanned Aerial Vehicle technology for the characterization of Mediterranean riparian forest. International Journalof Remote Sensing, 30: 19, pp. 4915 -4935 .

Chianucci, F., Disperati, L., Guzzi, D., Bianchini, D., Nardino, V., Lastri, C., Rindinella, A., Corona, P., 2015. Estimation of canopy attributes in beech forests using true colour digital images from a small fixed-wing UAV. International Journal of Applied Earth Observation and Geoinformation, Volume 47, May 2016, pp. 60-68, ISSN 0303-2434.

Chisholm, Ryan A., Jinqiang, Cui., Lum, Shawn K Y., Chen, Ben M., 2013. UAV LiDAR for below-canopy forest surveys. Journal of Unmanned Vehicle Systems, 01, pp. 61-68, 10.1139/juvs-2013-0017

Koh, LP., Wich, SA., 2012. Dawn of drone ecology: low-cost autonomous aerial vehicles for conservation. Trop Conserv Sci 5, pp. 121-132.

Lisein, J., Pierrot-Deseilligny, M., Bonnet, S., Lejeune, P., 2013. A photogrammetric workflow for the creation of a forest canopy height model from small unmanned aerial system imagery. Forests, 4(4), pp. 922-944.

Michez, A., Piégay, H., Lisein, J., Claessens, H., Lejeune, P., 2016. Classification of riparian forest species and health condition using multi-temporal and hyperspatial imagery from unmanned aerial system. Environmental Monitoring and Assessment. DOI:10.1007/s10661-015-4996-2.

Ollero, A., Merino, L., 2006. Unmanned aerial vehicles as tools for forest-fire fighting. For. Ecol. Manage. 234(1), pp. 263-274

Paneque-Galvez, J., McCall, MK., Napoletano, BM., Wich, SA., Koh, LP., 2014. Small drones for community-based forest monitoring: an assessment of their feasibility and potential in tropical areas. Forests 5(6), pp. 1481-1507.

Tang, L., Shao, G., 2015. Drone remote sensing for forestry research and practices. Journal of Forestry Research, 26(4), pp. 791-797. doi:10.1007/s11676-015-0088-y.
Wallace, L., Lucieer, A., Watson, Ch., Turner, D., 2012. Development of a UAV-LiDAR System with Application to Forest Inventory. Remote Sens, 4, no. 6, pp. 1519-1543.

Wallace, L., 2013. Assessing the stability of canopy maps produced from UAV-LiDAR data. Geoscience and Remote Sensing Symposium (IGARSS), IEEE International, Melbourne, VIC, 2013, pp. 3879-3882. doi: 10.1109/IGARSS.2013.6723679.

Zarco-Tejada, PJ., Diaz-Varela, R., Angileri, V., Loudjani, P., 2014. Tree height quantification using very high resolution imagery acquired from an unmanned aerial vehicle (UAV) and automatic 3D photo-reconstruction methods. Eur J Agron 55, pp. 89-99. 